\section{Molecular genetics of rhegmatogenous retinal detachment}

\author{
Abstract \\ Rhegmatogenous retinal detachment (RRD) \\ most commonly occurs as a spontaneous \\ event resulting from posterior vitreous \\ detachment, typically between the ages of \\ $40-70$ yrs. It is also a feature in some \\ inherited disorders, most commonly Stickler \\ syndrome. The relationship between these \\ inherited disorders and the spontaneous \\ cases is unclear. Here in particular we review \\ Stickler syndrome, and discuss the \\ differential diagnosis of Stickler, Wagner \\ and Marshall syndromes. Other rare \\ inherited disorders associated with RRD are \\ also briefly reviewed. \\ Eye (2002) 16, 388-392. doi:10.1038/ \\ sj.eye. 6700195
}

Keywords: retinal detachment; Stickler; Wagner; Marshall; collagen; vitreous

Rhegmatogenous retinal detachment (RRD) most commonly occurs as a spontaneous event resulting from posterior vitreous detachment, typically between the ages of 40 70 yrs. However in up to $10 \%$ of these cases the fellow eye will develop significant pathology in the form of RRD or horseshoe retinal tear. In addition RRD can occur in a number of inherited disorders. Both of these subgroups would imply an underlying structural predisposition to RRD. The most common of the inherited disorders with RRD is Stickler syndrome or arthroophthalmopathy. ${ }^{1}$ This disorder affects the type II/XI heterotypic collagen fibrils in cartilage and vitreous, usually causing both a skeletal and eye phenotype. This article will concentrate on our experience with such families, and will review other less common disorders also associated with RRD, some of which can sometimes be confused with Stickler syndrome.
Stickler syndrome (MIM 108300, 604841)

Stickler et al ${ }^{1}$ described a family with a dominantly inherited disorder with both a skeletal and eye phenotype. As well as progressive myopia and a high incidence of retinal detachment, affected individuals displayed abnormal epiphyseal development with premature degenerative changes to various joints. Subsequent analysis of such families linked the disorder to COL2A1 the gene for type II collagen, a major constituent of both cartilage and vitreous. ${ }^{2}$ Thus Stickler syndrome was related to other chondrodysplasias such as achondrogenesis, hypochondrogenesis, splondyloepiphyseal dysplasia and Kniest dysplasia, which result from dominant negative mutations in the COL2A1 gene. ${ }^{3}$ The first mutations characterised in Stickler syndrome all lead to premature termination codons (PTC), and so resulted in haploinsufficiency of type II collagen. ${ }^{4-6}$ This was also the case for the original family described by Stickler, where missplicing of intron/exon 17/18 resulted in a frameshift of the mRNA sequence. ${ }^{7}$

Although the phenotype of the syndrome can be highly variable, both between and within families, a congenital membraneous anomaly described by $\mathrm{Scott}^{8}$ can be seen in the vast majority of Stickler syndrome cases. Snead et $a l^{9}$ showed that in all cases, families with this vitreous phenotype were linked to the COL2A1 gene. In addition a smaller group of families with Stickler syndrome, but without the membraneous anomaly, were not linked to COL2A1. Our recent studies have shown that the families, studied by Snead et $a l^{9}$ and additional sporadic cases with the membraneous anomaly, all have mutations in COL2A1. ${ }^{10,11}$ In nearly all cases these, via a variety of different types of mutations, lead to premature termination condons and haploinsufficiency of type II collagen. Analysis of illegitimate COL2A1 mRNAs indicated that mutant transcripts were degraded by a process known as nonsense mediated decay 
(NMD). ${ }^{12}$ Because of the difficulty in obtaining tissue that expressed type II collagen, we studied COL2A1 mRNA from cultured skin fibroblasts. Even if a protein is not expressed in a particular tissue, its mRNA may still be present at very low levels, and PCR amplification of these so-called illegitimate transcripts can still be possible. Sequencing of amplified cDNA revealed loss of heterozygosity in the COL2A1 mRNAs when compared to the mutant sequence seen in genomic DNA. Incubating cells with protein synthesis inhibitors such as cycloheximide or emitine can inhibit NMD. These bind to the 605 and 405 ribosomal subunits, which are involved in the NMD process, and allow mutant mRNAs to accumulate. ${ }^{13}$ Treatment of cells with emitine therefore allows visualisation of both the normal and mutant cDNA sequence (by protecting the latter from NMD). When cells from patients with Stickler syndrome were analysed in this way, emitinetreated cells produced a heterozygous cDNA sequence, compared to the homozygous sequence in untreated cells (Figure 1). This indicated that the NMD process was operating on the COL2A1 mutant alleles in Stickler syndrome.

In three cases, the membraneous anomaly was seen where a dominant negative mutation (R365C) substituted a cysteine for arginine ${ }^{11}$ (unpublished results). Cysteine does not usually occur in the mature fibrillar collagen molecule. Similar mutations both in type II and type I collagens ${ }^{14,15}$ showed that cysteinecontaining collagen is poorly secreted. Thus, both the PTC and arginine to cysteine substitutions, lead us to believe that the membraneous anomaly is due to a lack of critical mass of type II collagen, during development of the eye, resulting in the clinical observation of a vestigial vitreous gel in the retrolental space. The $\alpha 1$ (II) chain also assembles with $\alpha 1(\mathrm{XI})$ and $\alpha 2(\mathrm{XI})$ alpha chains to form type $\mathrm{XI}$ collagen, ${ }^{16}$ so dominant negative changes such as R365C will also affect this molecule.

Some families with the membraneous anomaly presented with only minor or no skeletal phenotype. The COL2A1 gene is expressed in two forms, whereby exon 2 is alternatively spliced. It is absent in mature cartilage transcripts, but is retained in the eye. ${ }^{17,18}$ Mutations in this exon are therefore effectively removed from cartilage tissue, resulting in a predominantly ocular Stickler syndrome phenotype. ${ }^{10}$ Patients with this phenotype may have been mistaken for Wagner syndrome (see below). However all had the congenital membraneous anomaly and were clearly variants of Stickler syndrome rather than Wagner syndrome. The same phenotype can also result from other COL2A1 mutations (unpublished results).

Whereas type II collagen is a major component of cartilage and vitreous, type XI collagen is a
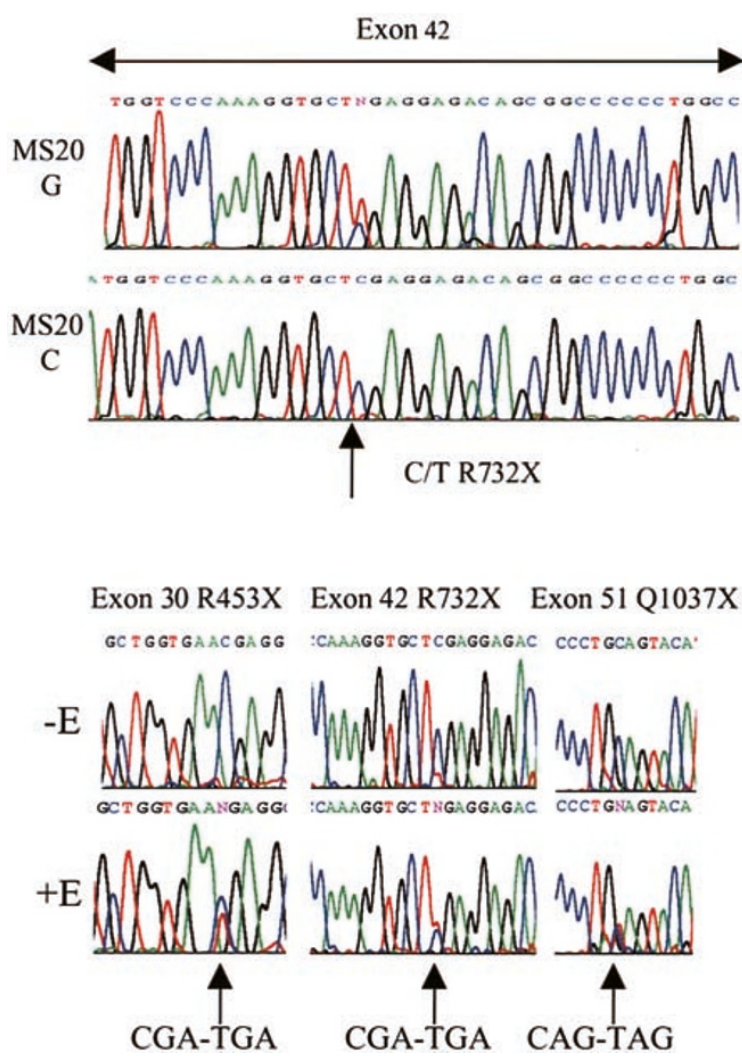

Figure 1 Premature termination codons result in nonsense mediated decay. A R742X heterozygous mutation seen in exon 42 of Genomic DNA (G) appears as homozygous normal, when illegitimate transcripts from the same individual are amplified as cDNA and sequenced (C). Heterozygous sequence from three different mutations (as indicated) can be retrieved by pretreatment of cells with emitine $(+E)$ prior to mRNA preparation. In all three cases these appeared homozygous normal without exposure to emitine (-E).

quantitatively minor component. Using rarer (type 2) families, which lacked the membraneous anomaly, linkage of one family to COL11A1, the gene for $\alpha 1(\mathrm{XI})$ collagen was demonstrated and the first mutation (Gly97Val) in this gene characterised. ${ }^{19}$ Analysis of two other families found an exon skipping mutation and a large multiexon deletion in COL11A1. ${ }^{20}$ All three of these families had a vitreous with a beaded appearance to its structure (Figure 2). Analysis of two sporadic cases with an identical phenotype also found mutations in the COL11A1 gene (unpublished results). Type (XI) collagen has a role in the regulation of collagen fibril assembly, controlling lateral growth and limiting fibril diameter. ${ }^{21}$ We suspect that mutations in this gene interfere with this regulation, resulting in thicker than normal fibrils and this is reflected in the appearance of the lamellae of the vitreous. Similar mutations in COL11A $1^{22,23}$ have also been described in Marshall syndrome (see below). However the vitreous 

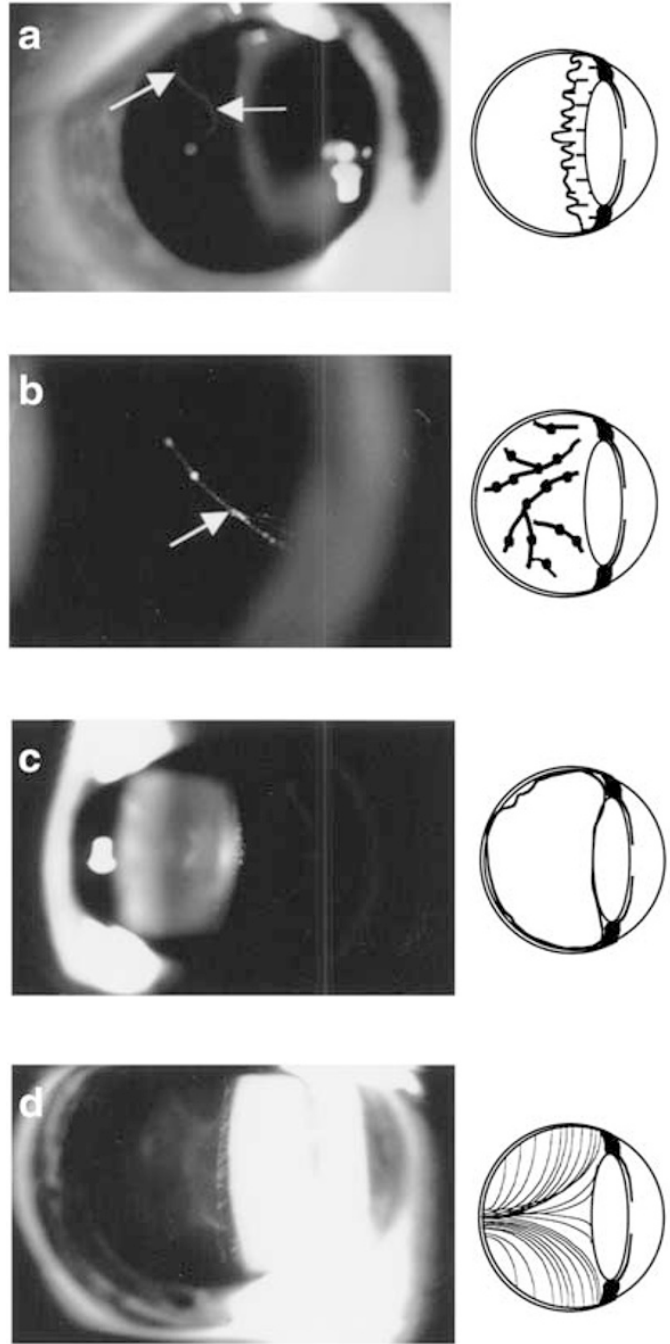

Figure 2 Vitreous phenotypes in Stickler syndrome (a) 'Membranous' congenital vitreous anomaly. Note vestigial gel occupying retrolental space and bordered by a distinct folded membrane (arrows). (b) 'Beaded' congenital vitreous anomaly seen in cases of COL11A1 mutations. Note irregularly thickened fibre bundles giving 'string of pearls or beaded' appearance (arrow). (c) 'Afibrillar' congenital vitreous anomaly seen in cases of COL2A1 L467F mutation. Note complete absence of visible fibre bundles. (d) Normal vitreous appearance. Note healthy compact homogenous fibrillar array. Reproduced with permission from Richards et al. Am J Hum Genet 2000; 67: 1083-1094, published by the University of Chicago Press. (c) 2000 by The American Society of Human Genetics. All rights reserved.

appearance of affected individuals was not described so that comparisons with type 2 Stickler syndrome are difficult to make. Whether all patients with this beaded vitreous phenotype have mutations in COL11A1 is unclear, as we have been unable to detect mutations in a number of similar cases. Other families are not linked to either COL2A1 or COL11A1 and so at least one other locus for Stickler syndrome exists. ${ }^{20,24}$
Another type XI collagen gene, COL11A2, is not expressed in the eye and mutations in it result in a non-ocular chondrodysplasia phenotype (MIM 184840).

\section{Wagner syndrome (MIM 143200)}

Wagner ${ }^{25}$ described a family with a dominantly inherited vitreoretinopathy. This syndrome is often confused with Stickler syndrome and consequently the phenotypic differences between the two have become blurred. A common term used to describe Wagner syndrome is vitreoretinopathy without systemic involvement. However in our opinion this definition does not differentiate between the two syndromes adequately, as Stickler syndrome can also present with minimal systemic features (see above). In most instances the vitreous changes described for Stickler syndrome can distinguish it from Wagner syndrome. In addition Wagner syndrome has changes in the retinal pigment epithelium (RPE), difficulties with night vision and visual field defects not seen in Stickler syndrome. Erosive vitreoretinopathy (ERVR) is a disorder very similar to Wagner syndrome. ${ }^{26} \mathrm{~A}$ constant finding in these patients is a translucence or erosion of the RPE. The incidence of RRD was higher in ERVR (73\%) compared to $18 \%$ in the original Wagner kindred.

Both Wagner syndrome and ERVR are linked to the same region of chromosome 5 and so may be allelic. ${ }^{26}$ Analysis of a candidate gene (CSPG2) in this region found a single base pair change, in one family, not present in 100 normal control chromosomes. ${ }^{27}$ However no mutation could be found in 17 other families. Whether these were all cases of Wagner syndrome, is however questionable, as they were described as having vitreoretinopathy without systemic involvement, and linkage to $5 \mathrm{q} 14.3$ was not informative in 14 cases. ${ }^{27}$ This phenotype might also result from certain mutations in COL2A1. We have recently sequenced the complete open reading frame of CSPG2 from an individual with Wagner syndrome and have also failed to detect any mutation (unpublished results). The disease locus for this syndrome remains to be resolved.

\section{Marshall syndrome (MIM 154780)}

Like Wagner syndrome, there has been debate regarding whether Marshall and Stickler syndrome are distinct entities. ${ }^{28,29}$ Marshall ${ }^{30}$ reported a large family showing autosomal dominant inheritance of cataracts, myopia, abnormal vitreous, midfacial hypoplasia, deafness and reduced sweating (anhydrosis). Two reports have characterised mutations of $\alpha 1(\mathrm{XI})$ collagen 
in cases of Marshall syndrome. ${ }^{22,23}$ These have associated skipping of 54-bp exons of COL11A1 with the syndrome. Other mutations in the same gene were said to result in mixed Marshall/Stickler phenotypes. ${ }^{23}$ Unfortunately the vitreous phenotypes in these cases were not described. Certain phenotypic traits appear to be more commonly associated with mutations of COL11A1 than COL2A1. ${ }^{23}$ These include the craniofacial abnormalities attributed to Marshall syndrome. However most of these traits can also result from mutations in COL2A1 and so determination of the disease gene locus from the facial phenotype is probably unreliable. As far as we are aware the molecular defect in the family originally described by Marshall has not yet been determined.

\section{Familial exudative vitreoretinopathy (MIM 133780, 305390, 605750)}

This is a rare ocular disorder with variable phenotype. Despite the name, RRD and falciform folds occur, as well exudative retinal detachment. ${ }^{31}$ Mutations of the Norrie disease gene have been found in the X-linked form of the disorder ${ }^{32}$ (MIM 305390). Although the mechanism by which the mutations result in the pathology is not fully understood, the autosomal dominant form of the disorder has been linked to two loci on chromosome 11 at $11 \mathrm{q} 13-23^{31}$ and $11 \mathrm{p} 12-13 .^{33}$

\section{Knobloch syndrome (MIM 267750)}

Knobloch syndrome is a rare recessive disorder with features similar to Stickler syndrome. Affected individuals have high myopia, retinal detachment, flat nasal bridge and midfacial hypoplasia and in addition occipital encephalocele. A homozygous mutation in COL18A1, the gene for type XVIII collagen, has been described leading to a premature termination codon in both alleles. ${ }^{34}$ The syndrome therefore represents a functional knockout of the COL18A1 gene. As yet little is known regarding the function of type XVIII collagen.

\section{Marfan syndrome (MIM 154700)}

Marfan syndrome is a dominantly inherited disorder, affecting the ocular, skeletal and cardiovascular systems. Common ocular problems include cornea plana, dislocation of the lens and myopia. These are associated with a greater risk of retinal detachment in this disorder. Mutations in FBN1, the gene encoding fibrillin 1, a component of the microfibrillar network, have been found to cause Marfan syndrome. ${ }^{35}$

\section{Dominantly inherited rhegmatogenous retinal detachment}

RRD can occur as a dominantly inherited trait. Whether these cases are related to the syndromes described above is unclear. One family referred to us as Stickler syndrome but without the membraneous anomaly was nevertheless linked to the COL2A1 gene. A mutation was found which converted lysine at position 467 to phenylalanine. ${ }^{11}$ Analysis of illegitimate transcripts demonstrated heterozygosity, which supported the observation of a dominant negative mutation. The change also resulted in a different 'afibrillar' phenotype, where the vitreous gel had formed but was optically empty. It is unclear whether the change is affecting secretion of collagen, interfering with collagen fibrillogenesis or disrupting interaction with other matrix molecules. Although originally referred with a diagnosis of Stickler syndrome, the minimal or absent systemic changes in this family, along with the lack of the membraneous vitreous anomaly may mean a classification of dominant rhegmatogenous retinal detachment is more appropriate. The involvement of type II collagen in families with DRRD remains to be explored, as does the association of 'normal' collagen haplotypes in the common isolated cases.

\section{Acknowledgements}

This work was presented at the XXXI Cambridge Ophthalmological Symposium 2001. It was supported by grants from The Stanley Thomas Johnson Foundation, The Guide Dogs for the Blind Association and the Isaac Newton Trust.

\section{References}

1 Stickler GB, Belau PG, Farrell FJ, Jones JD, Pugh DG, Steinberg AG, Ward LE. Hereditary progressive arthroophthalmopathy. Mayo Clinic Proc 1965; 40: 433-455.

2 Francomano CA, Liberfarb RM, Hirose T, Maumenee IH, Streeten EA, Meyers DA, Pyeritz RE. The Stickler syndrome: evidence for close linkage to the structural gene for type II collagen. Genomics 1987; 1: 293-296.

3 Spranger J, Winterpacht A, Zabel B. The type II collagenopathies: a spectrum of chondrodysplasias. Eur J Pediatr 1994; 153: 56-65.

4 Ahmad NN, Ala-Kokko L, Knowlton RG, Jimenez SA, Weaver EJ, Maguire JI et al. Stop codon in the procollagen II gene (COL2A1) in a family with the Stickler syndrome (arthro-ophthalmopathy). Proc Natl Acad Sci USA 1991; 88: 6624-6627.

5 Ahmad NN, McDonald-McGinn DM, Zackai EH, Knowlton RG, Larossa D, Dimascio J, Prockop DJ. A second mutation in the type II procollagen gene (COL2A1) causing Stickler syndrome (arthro 
ophthalmopathy) is also a premature termination codon. Am J Hum Genet 1993; 52: 39-45.

6 Brown DM, Nichols BE, Weingeist TA, Sheffield VC, Kimura AE, Stone EM. Procollagen II gene mutation in Stickler syndrome. Arch Opthalmol 1992; 110: 1589-1593.

7 Williams CJ, Ganguly A, Considine E, McCarron S, Prockop DJ, Walsh-Vockley C, Michels VV. A $\rightarrow \mathrm{G}$ Transition at the $3^{\prime}$ acceptor splice site of IVS17 characterises the COL2A1 gene mutation in the original Stickler syndrome kindred. Am J Med Genet 1996; 63: 461467.

8 Scott JD. Prevention and perspective in retinal detachment. Duke-Elder Lecture. Eye 1989; 3: 491-515.

9 Snead MP, Payne SJ, Barton DE, Yates JR, al-Imara L, Pope FM, Scott JD. Stickler syndrome: correlation between vitreo-retinal phenotypes and linkage to COL 2A1. Eye 1994; 8: 609-614.

10 Richards AJ, Martin S, Yates JRW, Scott JD, Baguley DM, Pope FM, Snead MP. COL2A1 exon 2 mutations: relevance to the Stickler and Wagner syndromes. $\mathrm{Br} J$ Ophthalmol 2000; 84: 364-371.

11 Richards AJ, Baguley DM, Yates JR, Lane C, Nicol M, Harper PS et al. Variation in the vitreous phenotype of Stickler syndrome can be caused by different amino acid substitutions in the $X$ position of the type II collagen GlyX-Y triple helix. Am J Hum Genet 2000; 67: 1083-1094.

12 Maquat LE. When cells stop making sense: effects of nonsense codons on RNA metabolism in vertebrate cells. RNA 1995; 1: 453-465.

13 Carter MS, Doskow J, Morris P, Li S, Nhim RP, Sandstedt $\mathrm{S}$, Wilkinson MF. A regulatory mechanism that detects premature nonsense codons in T-cell receptor transcripts in vivo is reversed by protein synthesis inhibitors in vitro. J Biol Chem 1995; 270: 28995-29003.

14 Eyre DR, Weis MA, Moskowitz RW. Cartilage expression of a type II collagen mutation in an inherited form of osteoarthritis associated with mild chondrodysplasia. J Clin Invest 1991; 87: 357-361.

15 Nuytinck L, Freund M, Lagae L, Pierard GE, HermannsLe T, De Paepe A. Classical Ehlers-Danlos syndrome caused by a mutation in type I collagen. Am J Hum Genet 2000; 66: 1398-1402.

16 Wu JJ, Eyre DR. Structural analysis of cross-linking domains in cartilage type XI collagen. J Biol Chem 1995; 270: $18865-18870$.

17 Sandell LJ, Morris N, Robbins JR, Goldring MB. Alternatively spliced type II procollagen mRNAs define distinct populations of cells during vertebral development: differential expression of the aminopropeptide. J Cell Biol 1991; 114: 1307-1319.

18 Bishop PN, Reardon AJ, McLeod D, Ayad S. Identification of alternatively spliced variants of type II procollagen in vitreous. Bioch Biophys Res Com 1994; 203: 289-295.

19 Richards AJ, Yates JRW, Williams R, Payne SJ, Pope FM, Scott JD, Snead MP. A family with Stickler syndrome type 2 has a mutation in the COL11A1 gene resulting in the substitution of glycine 97 by valine in $\alpha 1(\mathrm{XI})$ collagen. Hum Mol Genet 1996; 5: 1339-1343.

20 Martin S, Richards AJ, Yates JRW, Scott JD, Pope FM, Snead MP. Stickler syndrome: further mutations in COL11A1 and evidence for additional locus heterogeneity. Eur J Hum Genet 1999; 7: 807-814.
21 Blaschke UK, Eikenberry EF, Hulmes DJ, Galla HJ, Bruckner P. Collagen XI nucleates self-assembly and limits lateral growth of cartilage fibrils. J Biol Chem 2000; 275: 10370-10378.

22 Griffith AJ, Sprunger LK, Sirko-Osadsa DA, Tiller GE, Meisler MH, Warman ML. Marshall syndrome associated with a splicing defect at the COL11A1 locus. Am J Hum Genet 1998; 62: 816-823.

23 Annunen S, Korkko J, Czarny M, Warman ML, Brunner $\mathrm{HG}$, Kaariainen $\mathrm{H}$ et al. Splicing mutations of 54-bp exons in the COL11A1 gene cause Marshall syndrome, but other mutations cause overlapping Marshall/Stickler phenotypes. Am J Hum Genet 1999; 65: 974-983.

24 Wilkin DJ, Mortier GR, Johnson CL, Jones MC, de Paepe A, Shohat $\mathrm{M}$ et al. Correlation of linkage data with phenotype in eight families with Stickler syndrome. Am J Med Genet 1998; 80: 121-127.

25 Wagner H. Ein bisher unbekanntes Erbleiden des Auges (Degeneratio hyaloideo-retinalis hereditaria), beobachtet im Kanton Zurich. Klin. Monatsblatter fur Augenheilkunde 1938; 100: 840-857.

26 Brown DM, Graemiger RA, Hergersberg M, Schinzel A, Messmer EP, Niemeyer G et al. Genetic linkage of Wagner disease and erosive vitreoretinopathy to chromosome 5q13-14. Arch Ophthalmol 1995; 113: 671-675.

27 Perveen R, Hart-Holden N, Dixon MJ, Wiszniewski W, Fryer AE, Brunner HG et al. Refined genetic and physical localisation of the Wagner disease (WGN1) locus and the genes CRTL1 and CSPG2 to a 2- to $2.5 \mathrm{Cm}$ region of chromosome 5q14.3. Genomics 1999; 57: 219-226.

28 Ayme S, Preus M. The Marshall and Stickler syndromes: objective rejection of lumping. J Med Genet 1984; 21: 3438.

29 Opitz JM, Lowry RB. Lincoln vs Douglas again; comments on the papers by Curry et al, Greenberg et al, and Belmont et al (Editorial). Am J Med Genet 1987; 26: 69-71.

30 Marshall D. Ectodermal dysplasia: report of kindred with ocular abnormalities and hearing defect. Am J Ophthal 1958; 45: 143-156.

31 Kondo H, Ohno K, Tahira T, Hayashi H, Oshima K, Hayashi K. Delineation of the critical interval for the familial exudative vitreoretinopathy gene by linkage and haplotype analysis. Hum Genet 2001; 108: 368-375.

32 Chen Z-Y, Battinelli EM, Fielder A, Bundey S, Sims K, Breakefield XO, Craig IW. A mutation in the Norrie disease gene (NDP) associated with X-linked familial exudative vitreoretinopathy. Nature Genet 1993; 5: 180183.

33 Downey LM, Keen TJ, Roberts E, Mansfield DC, Bamashmus $\mathrm{M}$, Inglehearn CF. A new locus for autosomal dominant familial exudative vitreoretinopathy maps to chromosome 11p12-13. Am J Hum Genet 2001; 68: 778-781.

34 Sertie AL, Sossi V, Camargo AA, Zatz M, Brahe C, Passos-Bueno MR. Collagen XVIII, containing an endogenous inhibitor of angiogenesis and tumor growth, plays a critical role in the maintenance of retinal structure and in neural tube closure (Knobloch syndrome). Hum Mol Genet 2000; 12: 2051-2058.

35 Dietz HC, Cutting GR, Pyeritz RE, Maslen CL, Sakai LY, Corson GM et al. Marfan syndrome caused by a recurrent de novo missense mutation in the fibrillin gene. Nature 1991; 352: 337-339. 